\title{
Rotinas Familiares de Ribeirinhos Amazônicos: Uma Possibilidade de Investigação
}

\author{
Simone Souza da Costa Silva ${ }^{1}$ \\ Fernando Augusto Ramos Pontes \\ Thamyris Maués dos Santos \\ Universidade Federal do Pará \\ Julia Bucher Maluschke \\ Universidade de Fortaleza \\ Leila Said Assef Mendes \\ Daniela Castro dos Reis \\ Sarah Danielle Baia da Silva \\ Universidade Federal do Pará
}

\begin{abstract}
RESUMO - A rotina das famílias tem se revelado uma estratégia interessante que permite conhecer não apenas seu funcionamento, mas também o desenvolvimento de seus membros. Todavia, investigar rotinas constitui um desafio para os pesquisadores interessados nessa temática, principalmente quando se trata de grupos inseridos em contextos culturais diferenciados. Com o intuito de contribuir metodologicamente, o presente trabalho descreve um instrumento de investigação qualitativo (Questionário de Rotinas Familiares - QRF), utilizado para coletar dados de rotinas de famílias que vivem em uma comunidade ribeirinha amazônica, cuja característica principal é o isolamento geográfico e social. São apresentadas as etapas de construção do instrumento, as adaptações necessárias e o modo de organização dos resultados (Diagrama de Atividades Familiares - DAF), ilustrados a partir de um caso investigado.
\end{abstract}

Palavras-chave: rotinas familiares; comunidades ribeirinhas; instrumento de avaliação.

\section{Family Routines of Amazonia's Riverside People: A Possibility of Investigation}

\begin{abstract}
Family routines have been revealed as an interesting strategy that allows the knowledge not only of its operation, but also the development of its members. Nevertheless, investigating routines constitutes a challenge to researchers interested in this subject, mainly when it is about groups inserted in differentiated cultural contexts. In order to provide a methodological contribution, this work describes an instrument of qualitative investigation (IFR - Inventory of Family Routines). This instrument was used to collect data about the routines of families who live in an Amazonia's riverside community, and whose main feature is the geographical and social isolation. The steps of the instrument construction are presented along with the necessary adaptations and the manner of results organization (FAD - Family Activities Diagram), all of them illustrated through an investigative case.
\end{abstract}

Keywords: family routines; riverside communities; evaluation instrument.

Partindo da perspectiva sistêmica para averiguar as características dos grupos familiares, considera-se a família como um "sistema constituído por subsistemas que mantêm entre si relações de interdependência" (Minuchin, 1985, p. 289) que marcam o desenvolvimento dos sujeitos que o compõe. A dinâmica dessas relações se concretiza no cotidiano, nas rotinas das famílias, de modo que essas rotinas se tornam os principais indicadores das formas de organização típicas do grupo familiar (Fiese \& cols., 2002; Geertz, 1966).

Deste modo, o interesse científico pelas rotinas familiares é grande e seus achados têm permitido não apenas estabelecer definições básicas na área de família, mas também têm ratificado o impacto da rotina na organização do subsistema familiar e, em termos mais gerais, no desenvolvimento humano (Haugland, 2005; Nelson, 1981, 1996). Na tentativa

1 Endereço para correspondência: Rua Faria Rodrigues n ${ }^{\circ} 16$. Curió, Utinga. Belém, PA. CEP 66610-530. Fone: (91) 32769533, (91) 88538179.E-mail:simone.souza@pesquisador.cnpq.br. de definir operacionalmente o termo rotina e de validar cientificamente o conceito, Boyce, Jensen, James e Peacock (1983) produziram um instrumento cujo objetivo consistia em verificar a quantidade e a variedade de atividades cotidianas realizadas pela família com o maior nível de abrangência possível. Eles propuseram que as atividades rotineiras da família são "aqueles comportamentos observáveis e repetitivos que envolvem dois ou mais membros e que ocorrem de modo regular e previsível na vida familiar" (p. 194).

Com base em uma metodologia de investigação rigorosa, Boyce e cols. (1983) construíram o Inventário de Rotinas Familiares (IRF). Após um extenso levantamento bibliográfico acerca do tema, os pesquisadores observaram diretamente $o$ cotidiano de 15 famílias, em um período que variava de 3 a 7 dias em uma semana, 24 horas por dia. Tal metodologia lhes permitiu identificar as rotinas existentes em todos os lares visitados. O processo de desenvolvimento e validação do instrumento de coleta de dados foi demonstrado por Jensen, James, Boyce e Hartnett (1983), que propuseram um inven- 
tário com 28 questões, ou seja, relativamente rápido, e com índices consideráveis de validade e confiabilidade.

Todos os grupos familiares nos quais foi aplicado o IRF apresentaram elementos previsíveis e recorrentes em suas rotinas (Boyce \& cols., 1983; Jensen \& cols., 1983). Tal previsibilidade e recorrência são fatores universalmente encontrados nos estudos acerca das famílias, constituindo importantes preditores das atitudes e formas de pensamento das pessoas nas sociedades através do tempo (Boyce \& cols, 1983; Fiese \& cols., 2002; Haugland, 2005; Jensen \& cols., 1983).

Desde o trabalho de Boyce e cols. (1983), muitas pesquisas têm sido desenvolvidas com intuito de acessar a rotina, seja de indivíduos ou de grupos, como a família. Interessados em correlacionar as atividades rotineiras de jovens infratores com a incidência de delitos, Osgood, Wilson, O’Malley, Bachman e Johnston (1996) utilizaram um inventário de rotinas com 13 situações típicas do dia-a-dia, sendo que quatro categorias correspondiam a atividades de socialização desestruturadas com pares na ausência de uma figura de autoridade, tais como: passear de carro para se divertir, ficar com os amigos, ir a festas, passar noite fora de casa para se divertir. Foi observado que jovens infratores praticavam freqüentemente tais atividades.

Sytsma, Kelley e Wymer (2001) descreveram o processo de construção e teste do Child Routines Inventory (CRI). Os autores apresentam desde o levantamento das rotinas das crianças junto às mães, o qual gerou uma lista constituída por 885 itens, passando pelo processo de organização e redução desses itens, até a sua composição final com 28 itens. O conjunto de itens apresentados foi organizado em quatro fatores, a saber: rotina da vida diária, responsabilidades domésticas, disciplina rotineira e rotina de trabalho em casa. Por fim, as análises estatísticas revelaram consistência no instrumento e seu alto valor como medida de avaliação das rotinas infantis.

$\mathrm{Na}$ tentativa de construir uma ferramenta semelhante, mas cujo objetivo era avaliar especificamente a rotina de crianças pré-escolares de 1 a 5 anos, Wittig (2005) desenvolveu e validou o Child Routines Questionnaire: Preschool (CRQ-P). Considerando aspectos semelhantes àqueles destacados por Sytsma e cols. (2001), o CRQ-P é constituído por 35 itens, sendo que muitos são diretamente associados à rotina familiar, já que se trata da rotina de crianças ainda muito pequenas.

$\mathrm{O}$ interesse pela avaliação de atividades desenvolvidas por indivíduos em desenvolvimento tem sido objeto de investigação de pesquisadores que avaliam o orçamento de tempo de crianças e adolescentes em vários contextos (Larson \& Verma, 1999). Além do interesse pelas rotinas, essas pesquisas têm em comum as sofisticadas análises estatísticas de seus dados.

No Brasil Boehs, Grisotti e Aquino (2007) investigaram as rotinas de famílias com filhos lactentes de 6 meses a 2 anos, cujas mães trabalhavam fora de casa e utilizavam determinada Unidade Básica de Saúde em um município do Sul do Brasil. Para tanto, aplicaram um formulário semiestruturado constituído por quatro partes, sendo que uma dessas tinha por objetivo conhecer as rotinas diárias, semanais e mensais da mãe junto à família e à criança lactante. A análise dos dados permitiu organizá-los em duas categorias: sequência e tipos de atividades rotineiras, que são discutidos considerando a influência da variável gênero sobre os cuidados dispensados às crianças pequenas.

A despeito da enorme contribuição que esses trabalhos têm oferecido à comunidade cientifica, são evidentes os problemas metodológicos envolvidos na tarefa de investigar as rotinas de grupos familiares inseridos em contextos culturais diferentes daqueles onde comumente se realizam as pesquisas de desenvolvimento. Esse é um aspecto fundamental, haja vista que, sustentado na perspectiva sistêmica, compreendese que as rotinas de um dado grupo familiar são construídas com base no jogo de interdependência estabelecido pelo grupo familiar e o contexto (Bronfenbrenner, 1994/2002).

O reconhecimento da marca conferida pelos contextos no funcionamento dos grupos familiares e no desenvolvimento das pessoas acarreta dificuldades não apenas aos estudos que investigam as rotinas familiares, mas também àqueles que destacam o papel central ocupado pelo contexto. Hutz e Silva (2002), ao explorar essa dificuldade com crianças e adolescentes em situação de risco no Brasil, destacam a não-adaptação e validação de instrumentos e técnicas a essa realidade como um dos principais problemas. Para os autores, "continua-se a estudar o desenvolvimento normal das crianças brancas de classe média e a patologia dos negros, dos hispânicos, dos imigrantes e dos pobres em geral" (p. 74).

A dificuldade de conhecer as especificidades de alguns contextos culturais se deve em parte à diversidade de contextos existentes, principalmente em um país extenso territorialmente como o Brasil, e em parte à falta de recursos metodológicos disponíveis. É comum encontrar na literatura instrumentos pouco sensíveis às especificidades contextuais, o que pode gerar dados incompatíveis com a realidade que se pretende conhecer. Particularidades dos contextos e dos sujeitos podem dificultar a apreensão das peculiaridades das rotinas investigadas.

Essa discussão é muito pertinente no que se refere aos estudos que investigam as rotinas das famílias. Apesar do reconhecimento da importância desse constructo nos estudos de desenvolvimento, no Brasil ainda são poucos os trabalhos que descrevem de modo claro estratégias de investigação das rotinas familiares. Particularmente, é esse o caso de populações não urbanas, como aquelas que vivem às margens dos rios na Amazônia brasileira.

De acordo com Scherer (2004a), a Amazônia é composta por dois grandes tipos de ecossistemas: as áreas inundáveis compostas pelas terras de várzeas, os igapós e os furos; e pelas florestas de terra firme, tais como as florestas altas e densas, as florestas baixas, as savanas, os cerrados e os campos naturais.

Diferente do caboclo da terra firme, os ribeirinhos vivem em sua maioria à beira dos rios, igarapés, igapós e lagos que compõem o vasto e complexo estuário amazônico. $\mathrm{O}$ dia a dia dos "Povos das Águas" está condicionado ao ciclo da natureza, pois o fenômeno da enchente e da vazante regula em grande parte o seu cotidiano, de tal modo que o mundo do trabalho e das relações obedece ao ciclo sazonal. A convivência nesse ecossistema define grande parte do modo de vida dessa população (Scherer, 2004a).

As preocupações na vida cotidiana dos ribeirinhos são determinadas pelas cheias/vazantes dos rios, pelo sol e pela 
chuva, pelos dias e pelas noites. Sua temporalidade é própria de quem vive nas várzeas (Scherer, 2003, 2004b). O tempo é definido pela natureza e pela cultura, pelos mitos e tradições. A crença em diversos seres sobrenaturais tem influência sobre as atividades de caça e de pesca ribeirinha (Wagley, 1952). A reprodução dos modos de vida dessa população é assegurada por meio da história oral (Fraxe, 2000).

Muitas dessas comunidades ribeirinhas são marcadas por acentuado grau de isolamento e exclusão social. Com pouca organização social e baixo poder de influência política, e bastante distanciados dos grandes centros decisórios, os ribeirinhos são incluídos forçadamente nas políticas públicas gerais governamentais sem que as especificidades de seu modo de vida sejam consideradas. No geral, isso se reflete nos grandes problemas que os assolam na esfera econômica, de educação e de saúde.

Considerando que as famílias organizam seus subsistemas em torno de atividades contextualmente disponibilizadas, e que as especificidades características de determinados participantes devem ser consideradas nas reflexões metodológicas, o presente artigo se propõe a descrever o processo de construção de um instrumento - o Questionário de Rotinas Familiares (QRF) -, visando investigar as rotinas de famílias que vivem em uma comunidade ribeirinha na Amazônia. Além de descrever o QRF, pretende-se apresentar o modo de representação das informações coletadas denominado de Diagrama de Atividades Familiares (DAF).

\section{Método}

\section{Parâmetros teóricos de construção e avaliação do QRF}

Partindo da noção de que as atividades rotineiras são organizadas de acordo com os papéis e responsabilidades estruturados por cada contexto cultural e pela cultura de cada família (Serpell, Sonnenschein, Baker \& Ganapathy, 2002), entende-se que a investigação das rotinas deve assegurar informações relativas às atividades específicas, aos contextos interacionais e aos espaços determinados.

Esse parâmetro pode ser considerado no estudo de rotinas familiares que estão inseridas em diferentes grupos culturais. Todavia, a consideração desses aspectos é extremamente pertinente quando se investiga a rotina de famílias que, por determinadas restrições ou modos de vida, tais como os grupos ribeirinhos, tendem a desenvolver suas atividades em torno do núcleo familiar, cujos membros são confinados pelas cheias ao contexto da casa e o modo de produção extrativista distribui o trabalho no interior da família.

Foi com base nesse parâmetro inicial que se desenvolveu uma planilha do QRF (Silva, 2006), na qual constam, no espaço das linhas, os períodos de um dia, divididos em madrugada, manhã, tarde e noite, e no espaço destinado às colunas, a atividade realizada, o local, a companhia e observações complementares. A escolha desses três eixos de descrição (atividade, local e companhia) deveu-se à noção de que esses são aspectos fundamentais na estruturação de subsistemas relacionais no interior da família.
O ponto favorável dessa abordagem teórica é que se evita a concepção apriorística de estudo em função de unidades de categorias pré-dadas, tais como divisão da família em função de subsistema conjugal, parental, fraternal, por exemplo. Nesse construto, as categorias são resultantes dos dados de encontros interacionais em função das atividades, locais e companhias.

\section{Participantes e ambiente}

Dentre as várias comunidades ribeirinhas amazônicas, a que serve de ilustração para este trabalho está situada na Ilha do Marajó - Pará. Dezesseis municípios compõem a ilha, sendo que Ponta de Pedras é um dos mais pobres dessa região, pois apresenta os níveis mais baixos de renda per capita de toda a ilha e um dos mais baixos Índices de Desenvolvimento Humano (IDH = 0,652; PNUD, 2000).

No município de Ponta de Pedras, é possível encontrar várias comunidades ribeirinhas, dentre as quais, a do rio Araraiana. A pesquisa aqui descrita e que deu base à construção do QRF foi realizada com 10 famílias, moradoras dessa comunidade, em um total de 80 pessoas, sendo escolhidas as que se mostraram mais acessíveis à equipe de pesquisa.

De menor expressividade na bacia hidrográfica do município, o rio Araraiana situa-se próximo à Ponta do Malato, local que serviu como base para os pesquisadores, e tem como coordenadas: S0 1 $1^{\circ} 30^{\prime} 162^{\prime \prime}$ e W0 48 54' $728^{\circ}$ ". O rio Araraiana desemboca na baia do Marajó, cuja foz possui a extensão aproximada de 10,6 milhas marítimas (equivalente a 19,680 km). Não existe transporte sistemático para essa comunidade, sendo necessária a locação de barco para o acesso ao local. De Belém para a Ponta do Malato são 32,7 milhas marítimas (equivalente a $68,730 \mathrm{~km}$ ) e de barco, a duração do deslocamento se dá em torno de 5 a 6 horas de viagem.

Os ribeirinhos do Araraiana apresentam a mesma condição de isolamento e exclusão de populações com o mesmo perfil. Esse isolamento pode ser justificado com base nos seguintes fatores: (1) a inexistência de transporte sistemático para a região, exposto anteriormente; (2) a dificuldade de contato entre os próprios moradores do rio; e (3) a dificuldade de acesso à mídia.

No referente ao contato social entre os vizinhos, existem 22 residências ao longo do rio e a distância aproximada entre elas é de $300 \mathrm{~m}$. Embora esse intervalo possa ser considerado pequeno, o fato dos espaços entre as moradias ser caracterizada por áreas de várzea, ou seja, que recebem periodicamente a invasão das marés, torna difícil o deslocamento ao longo desses trechos. Em geral, essas áreas se mantêm na maior parte do ano alagadas, o que implica na custosa e perigosa comunicação terrestre entre os moradores. Os intercâmbios sociais entre as casas só podem ser feitos por meio fluvial, isto é, por meio de "casquinhos" ou "montarias" - canoas feitas de troncos de árvore que transportam no máximo quatro pessoas e que são bastante suscetíveis à maré.

Quanto às estratégias de sobrevivência, existe uma demarcação a partir do gênero, sendo que os homens geralmente se denominam extrativistas ou pescadores e grande parte das mulheres se diz dona de casa ou artesã; não há agricultura e duas famílias criam galinhas e porcos soltos. 
A renda familiar mensal está muito abaixo dos índices de miséria, o equivalente a $35 \%$ do valor do salário mínimo em 2004. A falta de renda suficiente reforça a exclusão social dessa população.

A dificuldade de obter uma renda que lhes permita sobreviver com maior dignidade é observada nas condições de moradia desse grupo de ribeirinhos. No rio Araraiana, as famílias residem em casas que são geralmente pequenas, com média de três compartimentos (sala, quarto e cozinha). Essas residências têm piso de madeira, mas as paredes algumas vezes são feitas de outros materiais, como palha trançada ou bucha de miriti, árvore típica da região cujo tronco serve para construir algumas casas e como "ponte" entre o barco e a terra firme. Algumas dessas residências não possuem paredes externas. O quarto é local de dormir da genitora e crianças, enquanto o pai dorme na sala ou na entrada da casa.

Como observado, os ribeirinhos do Araraiana apresentam um isolamento entre os próprios moradores da comunidade. Porém, existe um isolamento ainda mais ressaltado, no que se refere à interação com outras comunidades ou com os centros urbanos. Além da grande distância entre a capital e o rio Araraiana, o que por si só dificulta contatos mais constantes, essa população tem pouco ou nenhum acesso a mídias escritas, televisivas ou radiofônicas (Silva, 2006).

Dessa maneira, pode-se considerar que em termos interacionais, o rio atua como constritor e fonte de contato, uma barreira e ponte ambiental, criando e restringindo as possibilidades de interação. Para Harris (2000), o rio representa a "metonímia do ser ribeirinho", aquilo que ao mesmo tempo cria vínculos e isolamentos entre as pessoas dessas populações.

Outro aspecto importante de ser destacado diz respeito à baixa regulação das atividades dessas pessoas pelas horas. Um dado relevante é que no interior de toda a comunidade, que é constituída por 125 moradores, há somente três relógios, sendo somente um de pulso. A ausência desse utensílio caracteriza a população, o que pode dificultar a utilização dos mesmos parâmetros instrumentais aplicados em populações urbanas.

Assim, a peculiaridade dessa comunidade constitui um aspecto que delineia a relevância deste estudo. Acredita-se que, comparativamente às famílias dos meios urbanos, os membros familiares despendem maior parte do seu tempo no interior de suas residências, devido às dificuldades de interação e comunicação com outros grupos, o que pode produzir uma estrutura familiar tipicamente acomodada a este modo de vida. Diante de um contexto tão peculiar, é possível que surjam formas bastante específicas de viver cotidianamente, o que torna importante a investigação das rotinas.

\section{Procedimento}

A coleta de dados se iniciou após a submissão do projeto de pesquisa ao Comitê de Ética que aprovou por meio do parecer $n^{\text {o. }}$ 2716-06, sua execução. Desse modo, antes de aplicar os instrumentos que geraram os dados aqui apresentados, os participantes, na maioria analfabetos, ouviram a leitura do Termo de Consentimento Livre e Esclarecido feita pela pesquisadora. Não houve recusa em colaborar com a execução do trabalho.

As entrevistas de aplicação do QRF foram realizadas individualmente e cada membro da família respondia acerca de suas próprias atividades, à exceção das crianças mais jovens, cuja rotina foi informada pela mãe ou pelos cuidadores responsáveis. A maioria das famílias é estendida, de modo que a aplicação do QRF se ampliou a todos os membros da unidade familiar.

Solicitava-se ao entrevistado que descrevesse a seqüência de atividades típicas desenvolvidas, a companhia e o local em que eram desenvolvidas durante um dia da semana (segunda a sexta) e de um fim de semana (domingo).

Os dados do QRF foram sempre considerados em paralelo com as informações descritas nos diários de campo (DC), que permitiam identificar aspectos qualitativos das atividades de rotina realizadas pelos participantes. Os diários de campo eram escritos após as visitas periódicas às residências dos moradores da comunidade, tal como descrito por Mendes e cols. (2008).

\section{Resultados}

\section{Categorias de análise}

Com base no cotejamento dos dados encontrados e nos parâmetros teóricos estabelecidos, foi possível desenvolver oito categorias de atividades realizadas no interior das famílias, divididas em duas dimensões. A primeira dimensão condiz às atividades de subsistência e cuidados básicos referentes à unidade familiar, tais como: Subsistência Econômica (SE), Subsistência Alimentar (SA), Tarefa doméstica (TD) e Cuidado Físico (CF). Tais categorias tomaram como princípio a relação entre a unidade familiar e a forma como os seus subsistemas estão organizados para sua manutenção, divisão de responsabilidades e de papéis. Esse é particularmente o caso de famílias organizadas no modo de produção familiar.

A outra dimensão de atividades diz respeito a um conjunto de categorias de contextos de encontros familiares independentes dos modos de sobrevivência. Nesse sentido foram encontradas basicamente as seguintes subcategorias: Prática Religiosa (PR), Lazer, Brincar, Estudo. A definição das respectivas categorias pode ser verificada no Quadro 1.

Tendo posse dos dados coletados, foi montada uma planilha no software Microsoft Office Excel 2003, com as informações de cada participante, tais como o período do desenvolvimento da atividade, a verbalização do participante, a referida categorização da verbalização da atividade, os possíveis acompanhantes e o local em que era desenvolvida.

Todo enquadramento das respostas em categorias de atividades foi produzido com base em discussões e no acordo de ao menos duas das três pesquisadoras que coletaram os dados. Caso não houvesse concordância, eram consultados os orientadores do projeto mais geral em que o presente trabalho estava incluído. 
Quadro 1. Categorias de atividades desenvolvidas no subsistema familiar.

\begin{tabular}{|c|c|}
\hline Categorias de atividades & Definição \\
\hline Subsistência Econômica (SE) & Todas as atividades cujo objetivo era obtenção de recursos de natureza financeira (dinheiro). \\
\hline Subsistência Alimentar (SA) & $\begin{array}{l}\text { Todas as atividades envolvidas na aquisição e preparo de nutrientes. Considera-se, nesse caso, } \\
\text { somente aquisição de nutrientes existentes no entorno da residência e relativos à própria sobrevi- } \\
\text { vência, por exemplo, "caça", "pesca", "coleta de frutos" e "preparo de alimento". }\end{array}$ \\
\hline Tarefa Doméstica (TD) & $\begin{array}{l}\text { Toda tarefa relativa ao espaço da casa, à exceção do preparo de alimentos. São exemplos dessa } \\
\text { atividade: "varrer casa", "lavar louça", "apanhar lenha", "consertar casa" etc. }\end{array}$ \\
\hline Cuidado Físico (CF) & $\begin{array}{l}\text { Todas as tarefas relativas ao cuidado físico de outras pessoas, geralmente os filhos e irmãos. São } \\
\text { exemplos dessa atividade: "alimentar", "dar banho", "colocar para dormir" etc. }\end{array}$ \\
\hline Prática Religiosa (PR) & Todas as atividades de caráter religioso, desde "orar sozinho" a "participar de um culto". \\
\hline Lazer & $\begin{array}{l}\text { Atividades praticadas no período de tempo livre e que envolvem o exercício de algum diverti- } \\
\text { mento, entretenimento ou distração. São comportamentos dessa categoria: "conversar", "assistir } \\
\text { televisão", "jogar futebol", "visitar parentes" etc. }\end{array}$ \\
\hline Brincar & Todas as atividades praticadas de caráter lúdico infantil, tais como "brincar", "banho no rio". \\
\hline Estudo & Momento dedicado às tarefas escolares sejam elas realizadas dentro da escola ou na residência. \\
\hline
\end{tabular}

\section{Os problemas encontrados durante a aplicação e análise dos dados}

Com o intuito inicial de conhecer as rotinas existentes na comunidade do Rio Araraiana, foi empregado um Inventário de Rotinas (IR), utilizado anteriormente no contexto urbano (Coelho, 2005; Lemos, 2005). O IR consistia em uma planilha com 24 linhas e quatro colunas a serem preenchidas, sendo que no espaço das linhas constava o horário, disposto em escala de uma hora, e no espaço das colunas a atividade realizada em tal horário, o local, a companhia e observações complementares. O objetivo dos pesquisadores era fazer um orçamento de tempo das atividades, locais e companhias desenvolvidos por adolescentes de camadas populares. Na pesquisa do contexto urbano, os dados obtidos com o IR permitiram realizar uma análise quantitativa, uma vez que esses dados eram transferidos diretamente a uma planilha do programa Microsoft Office Excel 2003, possibilitando a análise do tempo gasto por categorias de atividade, local e companhia, bem como a sequência em que transcorriam.

Durante a aplicação do QRF na comunidade ribeirinha do Araraiana, contudo, observou-se que os entrevistados apresentaram dificuldade de precisar em termos de horário as atividades, os locais e as companhias. Posteriormente, o motivo dessa dificuldade foi percebido: como já descrito, poucas casas da região possuem relógios de parede e somente um morador possuía relógio de pulso. Os ribeirinhos do Araraiana organizam seu tempo a partir das demandas das atividades que devem desenvolver no decorrer de um dia, de modo que o horário parece não ser um regulador de suas práticas.

Na maioria dos casos, as atividades são desempenhadas em função das condições mais favoráveis ou das demandas para o seu exercício. Há uma clara cisão entre o que deve ser realizado pela manhã, como as atividades de subsistência (realizadas antes do raiar do sol) e as tarefas domésticas (desenvolvidas principalmente no período matutino); e, por outro lado, o que deve ocorrer ao final da tarde, como o futebol e 
as visitas. Outro fator que também interfere nas atividades desenvolvidas é o regime das marés, uma vez que os moradores realizam suas atividades dependendo do período do dia em que a maré esteja cheia ou seca, favorecendo ou não as atividades de pesca.

Outro problema encontrado está relacionado à necessidade de domínio que o entrevistador deve possuir durante o processo de entrevista. A quantidade, a qualidade e a confiabilidade dos dados coletados dependem da habilidade do pesquisador em manejar a pesquisa. É necessário estimular, motivar o participante, de modo a explorar o máximo possível os aspectos referentes à sua rotina. Parte dessa habilidade é desenvolvida em função de um contato mais prolongado com a dinâmica do local, atividades costumeiramente desenvolvidas, vocabulário e cultura geral. Nesse sentido, o QRF deve ser aplicado de forma paralela às observações do diário de campo. Esse procedimento auxilia o pesquisador a se familiarizar com os aspectos a serem explorados, bem como possibilita correlacionar dados verbalizados com observados.

No geral, a riqueza do dado coletado pode depender de processos de inserção ecológica do pesquisador no contexto. Este procedimento metodológico, proposto por Cecconello e Koller (2003), baseado no Modelo Bioecológico de Urie Bronfenbrenner (1994/2002), pressupõe um envolvimento contínuo do pesquisador com os participantes no contexto em que a investigação ocorre (Mendes \& cols., 2008).

\section{A representação dos subsistemas de atividades}

Para facilitar uma maior visualização dos dados, foram construídos no software "Smart Draw Suit Edition Version 7.0”, Diagramas de Atividades Familiares (DAF), que são formas de representação que envolvem a descrição em subsistemas intrafamiliares envolvidos no desempenho de uma atividade.

Para melhor representar as informações do DAF, optou-se pela apresentação da árvore genealógica do grupo que compartilhava uma residência. Os subsistemas de atividades em que os membros se envolviam foram contornados por linhas de espessuras diferentes, o que permite distinguir as categorias de atividades empreendidas. Essas são identificadas nas figuras a partir de descrições complementares realizadas no entorno. Sendo assim, as imagens permitem conhecer as tarefas e quem as faz, assim como os momentos de encontros, de convivência mais próxima ou de isolamento, além de prover reflexões úteis sobre a natureza e características dos encontros familiares.

Com objetivo de diferenciar a formação de subgrupos em função das rotinas estabelecidas durante a semana, foram feitos dois diagramas para cada família, sendo um para o dia da semana e outro para o fim de semana, mais especificamente o domingo.

A seguir será demonstrado o exemplo de uma família moradora do rio Araraiana, denominada Família A, em que foi empregada a metodologia de estudo demonstrada neste trabalho, com a apresentação das atividades realizadas em um dia de semana típico. Enfatiza-se que os nomes utilizados são fictícios a fim de manter a identidade dos participantes.

\section{Apresentação de um caso}

A Família A, do casal Bastos (B) e Deise (D), é um exemplo típico de família ribeirinha Araraiana e foi analisada por Silva (2006). Esse grupo é constituído pelo casal, três filhos e Mário (M), o irmão de Deise, e se encontra em um dos primeiros estágios do ciclo familiar, haja vista que a idade da segunda geração varia entre 1 a 4 anos. A esposa ainda é muito jovem, tendo apenas 22 anos, enquanto seu cônjuge tem 72 anos. Mário, o irmão mais novo de Deise, tem apenas 17 anos.

O DAF do grupo Bastos/Deise, visualizado na Figura 1 , representa as atividades realizadas em um dia de semana qualquer. O dia da família inicia com Bastos e Deise acordando e fazendo suas tarefas de asseio e, na seqüência, Deise prepara o café. Ressalta-se que o casal dorme em ambientes separados, Bastos na cozinha e Deise no quarto junto com as crianças. No DAF, essa observação está no alto da figura. O fato de o pai dormir em um cômodo separado, mais exposto a eventuais perigos externos, é um hábito comum atribuído ao gênero masculino nessa comunidade.

Logo em seguida, Bastos parte para as suas atividades de SE e/ou SA e Deise, para as atividades de TD, SA e CF. Os dois só voltam a se encontrar no período da tarde, após o retorno de Bastos de suas atividades realizadas sozinho, inclusive o almoço no mato. As atividades empreendidas solitariamente por Bastos estão circuladas por linha tracejada e as atividades empreendidas por Deise juntamente com as crianças estão contornadas por linha dupla continua.

A nítida divisão de tarefas empreendida pelo casal demonstra certa rigidez nas fronteiras de atividades estabelecidas entre os subsistemas e como o exercício de tais atividades determina os momentos de aproximação e afastamento do casal.

Não são muitas as atividades de Deise em TD e SA, visto que a casa não demanda grandes cuidados e não há diversidade de alimentos a serem preparados. Contudo, seu encargo diário se torna pesado quando se considera que sua principal atribuição no decorrer de toda manhã e tarde é o CF com suas crianças muito jovens [Luiza (L), 4 anos; Oscar (O), 2 anos e Ivo (I), 1 ano], como alimentar, vigiar, dar banho e colocar para dormir. Essas tarefas são de sua inteira responsabilidade, não sendo partilhadas com Mário e com Bastos. Observa-se apenas o auxílio de Luiza, sua filha mais velha que, apesar de ter apenas 4 anos de idade, cuida de seus irmãos mais novos durante as brincadeiras que realizam. No DAF, este subsistema está envolvido por linha grossa continua.

As crianças estão sempre no entorno de Deise durante a execução das atividades da mãe, seja explorando o ambiente, seja brincando juntas. Nota-se que constituem um subsistema separado, que realiza atividades particulares e passa grande parte do tempo em conjunto, o que é uma característica da socialização local. A parceria de brincadeiras desenvolvidas por irmãos possibilita a configuração do sistema fraternal como também a possibilidade de melhor estabelecimento do subsistema parental (mãe-filho mais novo), à medida que a mãe relata que enquanto eles estão entretidos nas brincadeiras pode cuidar do filho e da casa.

Por outro lado, pode-se supor que a relação estabelecida entre os irmãos funciona como um laboratório para a exe- 


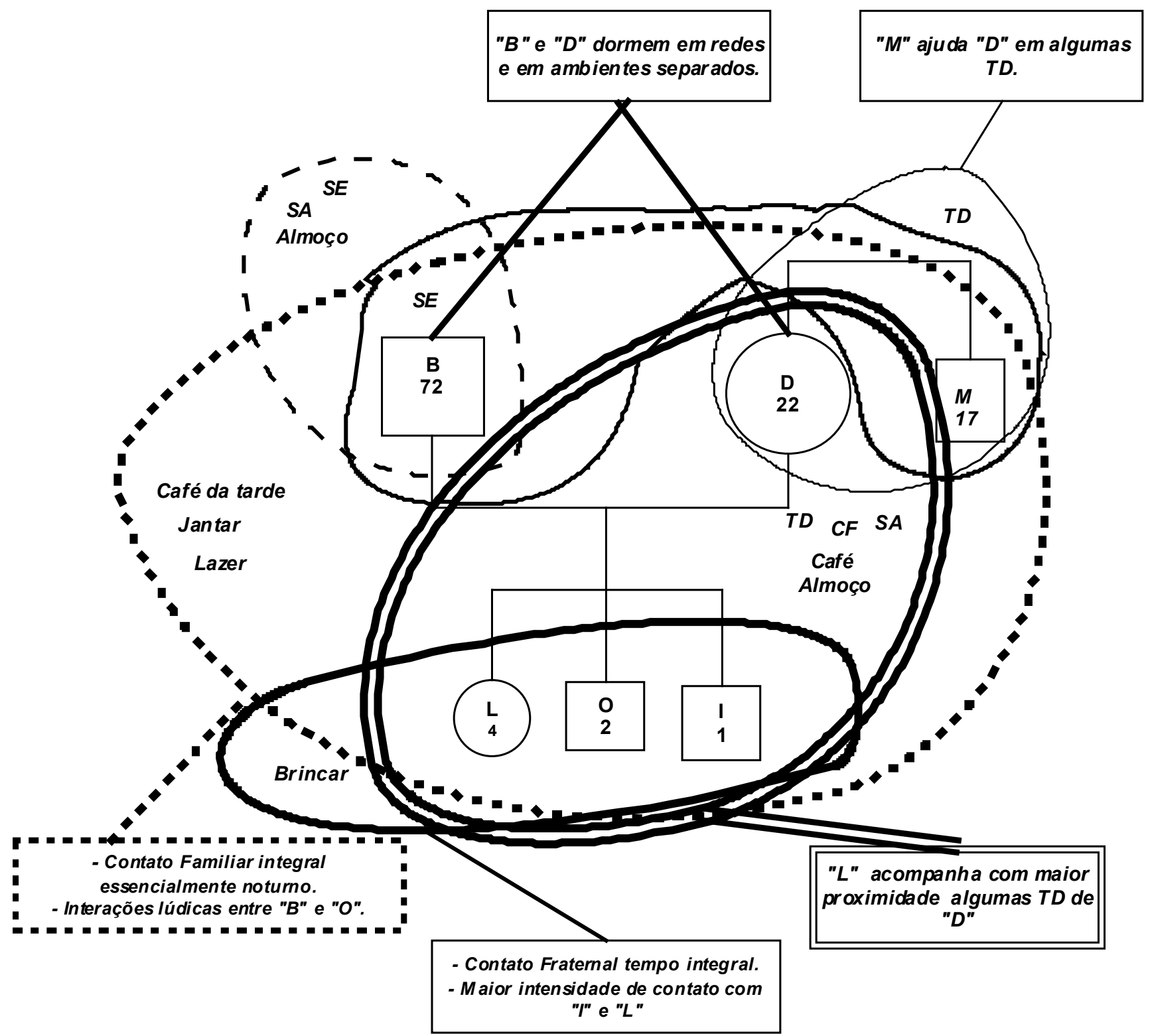

Figura 1. Diagrama de atividades familiares da Família A em um dia de semana.

cução de relações extra familiares, uma vez que o indivíduo passa pelo aprendizado de habilidades sociais e pessoais (Baía-Silva, 2006).

Após a volta de Bastos do mato (caça ou coleta) para casa, há um pequeno período de café da tarde no qual a família se reúne na casa. Em seguida, Bastos retoma suas atividades na companhia de Mário. Posteriormente, Mário visita seu pai e seus irmãos que moram nas proximidades, retornando apenas quando se aproxima a hora em que o jantar é servido. Mário auxilia tanto Deise nas TD, como apanhar lenha (período matutino), exposto no DAF em linha fina continua quanto Bastos nas SE, como o corte de tala (período vespertino), exposto em linha média continua. Mário se incorpora no subsistema familiar tanto exercendo tarefas com Bastos como com sua irmã.

O reencontro da família ocorre geralmente ao final da tarde, sendo inicialmente marcado pela realização de atividades em separado: se, por um lado, Bastos faz asseio, Deise prepara o jantar e, logo em seguida, dá banho nas crianças no rio. Mário, mais uma vez, auxilia Deise nas TD, como lavar a louça e varrer a casa.

$\mathrm{O}$ real encontro familiar aparentemente só acontece no jantar. Na seqüência há um período em que todos ficam juntos, falam e ouvem sobre coisas do dia. Somente no período noturno Bastos auxilia no CF com as crianças, já que fica interagindo e brincando com seus filhos até as crianças dormirem, principalmente com Oscar, o filho mais velho, com quem tem maior proximidade. No DAF, esse período de interação corresponde à linha pontilhada, que representa o momento de lazer e de encontro da família inteira. Deise põe as crianças para dormir e, logo em seguida, todos se recolhem para os seus devidos ambientes de repouso: Deise e as crianças no quarto, Mário no corredor e Bastos na cozinha.

Verifica-se que o DAF possibilita identificar não somente os subsistemas de organização familiar em função 
das atividades desenvolvidas, como também, resultante da configuração, aspectos relativos ao gênero e à faixa etária.

Percebe-se que o gênero é um fator que demarca quais serão as atividades desenvolvidas por cada membro familiar e, conseqüentemente, os subsistemas resultantes. Nesse sentido, as mulheres são responsáveis pelos cuidados domésticos e atividades executáveis dentro da casa, à medida que o homem trabalha e realiza suas ocupações nos espaços exteriores.

Percebe-se também a influência do gênero e da faixa etária nas atividades de Luiza, a filha mais velha, que cuida de seus irmãos mais novos durante as brincadeiras que realizam e também nas de Mário, que assume tanto tarefas destinadas às mulheres como também compartilha atividades com Bastos. Nas comunidades ribeirinhas ou mesmo em comunidades de organização mais simples e direta, os filhos mais velhos se tornam responsáveis pelo apoio aos seus progenitores nas tarefas que executam, dependendo do gênero a que pertença. Dessa maneira, as meninas aprendem muito cedo a exercer atividades relacionadas às tarefas de suas mães e os meninos a exercer atividades relacionadas às tarefas de seus pais. Há uma iniciação em papéis de gênero, sendo que no caso feminino parece ser mais prematuro e intenso (Segall \& cols., 1990). Supõe-se que o exercício de tais tarefas possibilite a conformação de subsistemas mãe-filha mais velha, irmão-irmã. Nesse sentido, comparando a diversidade de subsistemas participantes pela mãe e pelo pai, percebe-se que o da mãe é mais variado, de modo que é possível supor que a mãe medeia a relação entre os subsistemas.

\section{Discussão}

As pesquisas em desenvolvimento humano e relações familiares ainda apresentam maior ênfase de estudos em contextos urbanos, nas sociedades industrializadas (Hutz \& Silva, 2002). Os instrumentos desenvolvidos para investigar os subsistemas familiares apresentam-se artificiais em contextos não urbanos e consideram somente populações letradas e, por isso, necessitam ser adaptados às especificidades culturais.

Investigações em contextos rurais como a peculiar comunidade ribeirinha do Rio Araraiana, caracterizada pelo isolamento, possibilita um conjunto de questões sobre a organização familiar e o desenvolvimento infantil que demandam metodologias peculiares. Desse modo, foram realizadas adaptações metodológicas com base nas características da população e do contexto cultural em que esta se situa.

Por se entender que é imprescindível considerar a complexidade do grupo, contextualizando-o social, histórica e culturalmente (Böing, Crepaldi \& Moré, 2008), a produção do QRF e do DAF se sustentou primordialmente nas peculiaridades regionais com o intuito de construir uma metodologia válida para o contexto ribeirinho amazônico. $\mathrm{O}$ acesso aos dados e a demonstração das informações foi possível somente a partir da construção de um inventário adaptado à forma como os moradores compreendem e organizam o seu tempo, o QRF. A representação do material coletado, o DAF, demandou um sistema de categorias adaptado às atividades desenvolvidas e à organização destas em subsistemas.
Partindo da necessidade de estudar o desenvolvimento no contexto, foi fundamental que esta pesquisa efetivada em ambiente natural passasse por critérios de validade ecológica, ou seja, que "medisse de fato aquilo a que se pretendia medir" (Bronfenbrenner, 1994/2002, p. 24), levando em consideração as percepções do participante da pesquisa acerca do fenômeno investigado. Validar ecologicamente o QRF significou compreender as informações obtidas por meio da aplicação desse instrumento, inseridas no seu contexto de execução, sem a imposição de preconceitos e pressupostos do pesquisador que possam deturpar a qualidade dos dados. Validar ecologicamente o DAF denotou que este meio de representação apresentou de maneira mais próxima ao real um dia típico no cotidiano de uma família ribeirinha, desvendando as interações e momentos em que tais trocas ocorreram.

$\mathrm{O}$ enquadramento dos encontros familiares em função das atividades desenvolvidas pelos subsistemas possibilita uma aproximação da estrutura e da dinâmica das famílias ribeirinhas. Contudo, entende-se que tal representação pode ser muito útil para investigação de outras temáticas, como o estudo de questões de gênero, divisão de papéis, função e envolvimento paterno e materno, relações fraternas, conjugais etc.

A descrição dos dados por meio do DAF, como aqui proposta, pode ser utilizada também para fins de comparações de elementos mais dinâmicos, por exemplo, em diferentes momentos do ciclo de vida familiar. A aplicação do QRF em períodos distintos das transições normativas e não normativas, e a conseqüente representação de tais momentos em DAF, possibilitará a verificação dos arranjos de subsistemas familiares em cada período do ciclo de vida e momentos de transições ecológicas. Essas considerações vão além das questões contextuais aqui levantadas, sendo pertinentes tanto em contextos rurais como em contextos urbanos.

As categorias construídas a partir das atividades descritas no QRF foram fundamentais para organizar as disposições dos dados no DAF. Contudo, pode-se verificar limites da representação do DAF, já que ela não possibilita a dinâmica seqüencial da rotina e não dá indicadores sobre a qualidade que os momentos são experienciados pelos participantes. Por esse motivo, sempre em paralelo com o DAF, é fundamental uma descrição cursiva da seqüência em que os eventos se sucedem. Nessa descrição, a sequência pode ser relatada e é possível ao pesquisador expor elementos que possam ser indicadores de como os momentos vividos são percebidos.

Entretanto, a importância maior do método de pesquisa não se constitui apenas pelo instrumento em si, mas pela maneira como foi utilizado no local, isto é, integrando as características específicas da comunidade. O método foi utilizado com o objetivo de proporcionar ao pesquisador uma aproximação da realidade, envolvendo os moradores entrevistados e tornando-os mais seguros de sua participação na pesquisa. Para Flick (citado por Günther, 2006), a pesquisa qualitativa marca a coleta de dados pelo "Princípio da abertura", já que se utiliza de um conjunto de métodos e técnicas de acordo com as necessidades suscitadas pelo objetivo, e não um método padronizado único.

É evidente que o presente artigo pretende contribuir com as pesquisas que estudam família à medida em que apresenta as etapas de construção do instrumento, as adaptações que 
foram feitas e o modo de organização dos resultados (DAF), que são ilustrados por meio de um dos casos investigados. Todavia, o objetivo principal é servir de inspiração para a construção de instrumentos de investigação sensíveis às características peculiares dos diferentes microcontextos que compõem o extenso território brasileiro.

\section{Referências}

Baía-Silva, S. D. (2006). Diferenças de gênero na interação entre irmãos em uma comunidade ribeirinha amazônica. Dissertação de Mestrado, Universidade Federal do Pará, Belém.

Boehs, A. E., Grisotti, M., \& Aquino, M. W. (2007). Routines in families with infants. Revista Latino-Americana de Enfermagem, 15, 902-908.

Böing, E., Crepaldi, M. A., \& Moré, C. L. O. O. (2008). Pesquisa com família: aspectos teórico-metodológicos. Paidéia, 18, 251-266.

Boyce, W. T., Jensen, E. W., James, S. A., \& Peacock, J. L. (1983). The family routines inventory: Theoretical origins. Social Science and Medicine, 17, 193-200.

Bronfenbrenner, U. (2002). A ecologia do desenvolvimento humano: experimentos naturais e planejados (M. A. V. Veronese, Trad.). Porto Alegre: Artmed. (Trabalho original publicado em 1994)

Cecconello, A., \& Koller, S. H. (2003). Inserção ecológica na comunidade: proposta metodológica para o estudo de famílias em situação de risco. Psicologia: Reflexão e Crítica, 16, 515-524.

Coelho, K. H. L. (2005). O lazer em adolescentes: reflexões acerca de desenvolvimento. Dissertação de Mestrado, Universidade Federal do Pará, Belém.

Fiese, B., Tomcho, T., Douglas, M., Josephs, K., Poltrock, S., $\&$ Baker, T. (2002). A review of 50 years of research on naturally occurring family routines and rituals: Cause for celebration? Journal of Family Psychology, 16, 381-390.

Fraxe, T. J. P. (2000). Homens anfíbios: uma etnografia do campesinato das águas. São Paulo: Annablume.

Geertz, C. (1966). Religion as a cultural system. Em M. Banton (Org.), Anthropological approaches to religion (pp. 1-46). London: Tavistock.

Günther, H. (2006). Pesquisa qualitativa versus pesquisa quantitativa: esta é a questão? Psicologia: Teoria e Pesquisa, 22, 201-210.

Harris, A. G. (2000). Life on the Amazon: The anthropology a brazilian peasant village. New York: Oxford University Press/ The British Academic.

Haugland, B. S. M. (2005). Recurrent disruptions of rituals and routines in families with paternal alcohol abuse. Family Relations, 54, 225-241.

Hutz, C. S., \& Silva, D. F. M. (2002). Avaliação psicológica de crianças e adolescentes em situação de risco. Avaliação Psicológica, 1, 73-79.

Jensen, E. W., James, S. A., Boyce, W. T., \& Hartnett (1983). The family routines inventory: Development and validation. Social Science and Medicine, 17, 201-211.

Larson, R. W., \& Verma, S. (1999). How children and adolescents spend time across the world: Work, play, and developmental opportunities. Psychological Bulletin. 125, 701-736

Lemos, R. M. F. (2005). Rotinas e rituais familiares de uma população de baixa renda pertencente à Região Amazônica. Dissertação de Mestrado, Universidade Federal do Pará, Belém.
Mendes, L. S. A., Pontes, F. A. R., Silva, S. S. C., BucherMaluschke, J. S. N. F., Reis, D. C., \& Baía-Silva, S. D. (2008). Inserção ecológica no contexto de uma comunidade ribeirinha amazônica. Revista Interamericana de Psicologia. 42, 1-10.

Minunchin, P. (1985). Families and individual development: Provocations from the field of family therapy. Child Development, 56, 289-302.

Nelson, K. (1981). Social cognition in a script framework. Em J. H. Flavell \& L. Ross (Eds.), Social cognitive development (pp. 97-118). New York: Cambridge University Press.

Nelson, K. (1996). Language in cognitive development: The emergence of the mediated mind. New York: Cambridge University Press.

Osgood, D. W., Wilson, J. K., O’Malley, P. M., Bachman, J. G., \& Johnston, L. D. (1996), Routine activities and individual deviant behavior. American Sociological Review, 61, 635-655.

PNUD - Programa das Nações Unidas para o Desenvolvimento (2000). Relatório de desenvolvimento humano. Retirado em 15/01/2005, de http://www.undp.org.br/HDR/HDR2000/rdh2000/ default.asp.

Segall M. H., Dasen, P. R., Berry, J. W., \& Poortinga, Y. H. (1990). Human behavior in global perspective: An introduction to cross-cultural psychology. Boston: Allyn \& Bacon.

Serpell, R., Sonnenschein, S., Baker, L., \& Ganapathy, H. (2002). Intimate culture of families in the early socialization of literacy. Journal of Family Psychology, 16, 391-405.

Scherer, E. F. (2003). Políticas sociais para os Povos das Águas. Cadernos do CEAS, 207, 91-107.

Scherer, E. F. (2004a, maio). O defeso e a defesa do meio ambiente. Trabalho apresentado no II Congresso da Associação Nacional de Pós-Graduação e Pesquisa em Ambiente e Sociedade e no II Congresso da Associação de Pesquisa e Pós-Graduação em Ambiente e Sociedade. Indaiatuba, São Paulo.

Scherer, E. F. (2004b). Mosaico Terra-Água: a vulnerabilidade social ribeirinha na Amazônia. [Resumo]. Em Faculdade de Economia da Universidade de Coimbra (Org.), Anais do VIII Congresso Luso-Afro-Brasileiro de Ciências Sociais. Coimbra: Universidade de Coimbra.

Silva, S. S. C. (2006). Estrutura e dinâmica das relações familiares de uma comunidade ribeirinha da região amazônica. Tese de Doutorado, Universidade de Brasília, Brasília.

Sytsma, S. E., Kelley, M. L., \& Wymer, J. H. (2001). Development and initial validation of the child routines inventory. Journal of Psychopathology and Behavioral Assessment, 23, 241251.

Wagley, C. (1952). Man in the Amazon. Gainesville, FL: The University Press of Florida.

Wittig, M. M. (2005). Development and validation of Child Routines Questionnaire: Preschool. Tese de Doutorado, Louisiana State University, Louisiana. 